AperTO - Archivio Istituzionale Open Access dell'Università di Torino

\title{
Rheumatoid arthritis: Biological therapy other than anti-TNF
}

\section{This is the author's manuscript}

Original Citation:

Availability:

This version is available http://hdl.handle.net/2318/1545602

since 2016-10-04T11:08:43Z

Published version:

DOI:10.1016/j.intimp.2015.03.019

Terms of use:

Open Access

Anyone can freely access the full text of works made available as "Open Access". Works made available under a Creative Commons license can be used according to the terms and conditions of said license. Use of all other works requires consent of the right holder (author or publisher) if not exempted from copyright protection by the applicable law. 
This Accepted Author Manuscript (AAM) is copyrighted and published by Elsevier. It is posted here by agreement between Elsevier and the University of Turin. Changes resulting from the publishing process - such as editing, corrections, structural formatting, and other quality control mechanisms - may not be reflected in this version of the text. The definitive version of the text was subsequently published in INTERNATIONAL

IMMUNOPHARMACOLOGY, 27 (2), 2015, 10.1016/j.intimp.2015.03.019.

You may download, copy and otherwise use the AAM for non-commercial purposes provided that your license is limited by the following restrictions:

(1) You may use this AAM for non-commercial purposes only under the terms of the CC-BY-NC-ND license.

(2) The integrity of the work and identification of the author, copyright owner, and publisher must be preserved in any copy.

(3) You must attribute this AAM in the following format: Creative Commons BY-NC-ND license (http://creativecommons.org/licenses/by-nc-nd/4.0/deed.en), 10.1016/j.intimp.2015.03.019

The publisher's version is available at:

http://linkinghub.elsevier.com/retrieve/pii/S1567576915001216

When citing, please refer to the published version.

Link to this full text:

http://hdl.handle.net/2318/1545602 


\section{Rheumatoid arthritis: Biological therapy other than anti-TNF}

Daniela Rossi, Vittorio Modena, Savino Sciascia, Dario Roccatello, Center of Research of Immunopathology and Rare Diseases (CMID), Department of Rare, Immunologic, Hematologic and Immunohematologic Diseases, Giovanni Bosco Hospital, Turin, Italy

Abstract

Rheumatoid arthritis (RA) is one of the most common autoimmune diseases and is characterized by synovitis that causes joint damage. The introduction of biologic agents has made it possible to induce remission in many patients and inhibit joint damage. Activated T cells in RA patients proliferate and stimulate the production of pro-inflammatory cytokines including tumor necrosis factor (TNF) and interleukin 6 that play important roles in RA pathogenesis. The most widely used biologic agents indicated for RA inhibit the activity of TNF. However, newly developed biologic drugs targeting different pathways are now currently part of the therapeutic options to induce remission in patients with RA. The present review focuses on biologic agents directed at molecular targets different from TNF and addresses the possible advantages of these drugs.

Keywords

Rheumatoid arthritis; Abatacept; Rituximab; Tocilizumab; Anti-IL6

\section{Introduction}

Rheumatoid arthritis (RA) is one of the most common autoimmune diseases and is characterized by synovitis that causes joint damage. The introduction of biologic agents has made it possible to induce remission in many patients and inhibit joint damage. Therefore, it is important to assess the long-term outcomes of treatment with biologic therapies, to ensure that they are safe and tolerable and continue to offer clinical benefit. Activated T cells in RA patients proliferate and stimulate the production of proinflammatory cytokines [1], [2], [3] and [4] including tumor necrosis factor (TNF) and interleukin 6 that play important roles in RA pathogenesis. The most widely used biologic agents indicated for RA inhibit the activity of tumor necrosis factor (TNF). However, newly developed biologic drugs target interleukins (ILs), especially IL 6. Moreover, RA treatments targeting B and T cells have also been a focus of research, based on the profile of serological markers, including rheumatoid factor (RF) and anti-citrullinated cyclic peptide (anti-CCP), and the results of studies show infiltration of numerous CD4-positive T cells and expression of major histocompatibility complex (MHC) class II molecules in the synovial membrane [5]. Recent studies also revealed the importance of T-helper cells (Th)17 [6]. The present review focuses on biologic agents directed at molecular targets different from TNF and addresses the possible advantages of these drugs.

\section{Abatacept}

Abatacept (ABA) is a soluble recombinant human CTLA 4-Ig fusion protein comprising the extracellular domain of human CTLA-4 and a fragment of the FC domain of human IgG1 that selectively modulates the CD80/CD86:CD28 co-stimulatory signal required for full T-cell activation [7]. The unique upstream mechanism of $A B A$ impacts downstream inflammatory mediators and autoantibodies. For instance, reverse signaling to antigen-presenting cells (APCs) upon binding of CTLA 4-Ig to CD80/CD86 might also interfere with APC activation and function [8] and [9]. Whether such signaling or other CTLA 4-Ig-mediated effects contribute to a beneficial or adverse outcome, is not entirely clear so far. ABA has demonstrated significant improvements in both clinical efficacy and physical function, and has been shown to significantly reduce the progression of structural damage in 1-year, blinded, randomized, placebo-controlled trials of patients 
with established RA and an inadequate response to methotrexate (MTX) [10], [11] and [12]. ABA was initially available as an intravenous (IV) formulation. More recently, a subcutaneous (SC) formulation has also become available.

Multiple measures of efficacy were examined to evaluate the impact of treatment on multiple aspects of the disease, in addition to assessing clinical, functional, and HRQoL outcomes individually. At year $7,>40 \%$ of all patients achieved remission together with normalized $\mathrm{mHAQ}$. These data, which evaluated the response to treatment from different endpoints, suggest that the clinical efficacy benefits seen with $A B A$ plus MTX are accompanied by improvements in function and HRQoL that are meaningful to patients [13]. In combination with MTX, ABA proved to be able to deliver significant clinical benefits that were maintained over the long term, in patients with established RA and an inadequate response to MTX. ABA is currently prescribed to patients with RA uncontrolled by normal doses of existing disease-modifying antirheumatic drugs (DMARDs). The dosing regimen is based on patient weight (500 mg for $<60 \mathrm{~kg}, 750 \mathrm{mg}$ for $60-100 \mathrm{~kg}$, and $1000 \mathrm{mg}$ for $>100 \mathrm{~kg}$ ). The SC ABA is administered at a dose of $125 \mathrm{mg} /$ week. Due to a greater impact on naïve T cells, there is a rationale for the use of ABA in early RA. Importantly, some patients also experienced long lasting normalization of physical function and HRQoL. These findings support the use of ABA in patients with RA and an inadequate response to MTX, to obtain early, effective, and sustained clinical and functional outcomes. Of interest, cohort studies suggest a role for ABA administered as a monotherapy, and we achieved results comparable to the combination therapy in five patients who had experienced a definite increase of liver enzymes by both MTX and Azatioprine (manuscript submitted). ABA has a favorable safety profile, particularly in relation to serious (including opportunistic) infections in comparison with anti-TNF agents [14], [15], [16], [17] and [18]. The most common infections reported are pneumonia, urinary tract infection and cellulitis. As regards the risk of malignancies, the reported malignancy rates were not higher in patients treated with ABA than in those not treated with biological agents. Antibodies to $A B A$ developed in $\leq 3 \%$ of patients, with no association between immunogenicity and adverse events [19].

\section{Tocilizumab}

Tocilizumab (TCZ), a recombinant humanized anti-human IL-6 receptor monoclonal antibody, provides another alternative to anti-TNF- $\alpha$ therapy [20]. TCZ was introduced in 2010 for the treatment of RA [21] and has been approved for use in patients with active moderate to severe disease who have previously failed DMARDs [22]. IL-6 is a pleiotropic cytokine with various biologic activities, including induction of the acute-phase reaction, regulation of the immune response and promotion of hematopoiesis [23] and [24]. In RA patients, elevated levels of IL-6 seen in the serum and synovial fluid of affected joints [25], [26] and [27] are associated with disease activity, clinical manifestations of RA and joint destruction [28], [29] and [30]. The inhibition of IL- 6 signals by TCZ reduces systemic inflammation, RA synovitis, and bone and cartilage damage, and may have beneficial cardiovascular effects. The antibody was humanized by grafting a complementarity-determining region from a mouse anti-human IL-6R mAb. TCZ has been shown to bind to the membrane-bound and soluble forms of human IL-6R, and to inhibit IL-6 function [31]. TCZ can be administered in monotherapy without loss of efficacy when patients do not tolerate methotrexate or synthetic DMARDs. TCZ, either as monotherapy or in combination with MTX, was significantly more efficacious than MTX alone [32] and it is possibly superior to adalimumab in monotherapy. The FDArecommended dose is $4 \mathrm{mg} / \mathrm{kg}$ administered via the IV route every 4 weeks, and $162 \mathrm{mg}$ administered via the subcutaneous route every other week, followed by an increase to $8 \mathrm{mg} / \mathrm{kg}$ (i.v., q4w) or $162 \mathrm{mg}$ (s.c., qw) based on clinical response [33] and [34]. SC formulations of biologic DMARD have been developed in order to facilitate their use outside hospitals by permitting self-administration. 
TCZ might be particularly effective for RA patients with a high systemic inflammatory response, anemia, AA amyloidosis and other diseases mediated by IL- 6 and the European League Against Rheumatism (EULAR) 2013 update recommends TCZ use as a first biologic agent for monotherapy (without MTX) [35]. TCZ is highly effective with an ACR/EULAR remission rate of $35.1 \%$ and drug continuation rate at 3 years of $68.2 \%$ in routine clinical practice. Among the patients with remission, the majority remained in remission or had low disease activity. In general, TCZ was well tolerated in clinical trials for monotherapy and in combination with MTX or as DMARD [36] administered via IV or SC routes [37]. The safety profile is similar to anti-TNF in both the short term and the long term. Nevertheless, a number of side effects have been reported in patients treated with TCZ. The most common adverse events were infection, gastrointestinal complaints, rash, headache and biochemical abnormalities (including increased levels of lipids and liver enzymes) and infusion/hypersensitivity reactions [38]. In patients with considerable comorbidity TCZ therapy has been associated with an increased risk of gastrointestinal perforation, opportunistic infections and tuberculosis [33]. Apart from RA, TCZ has also been used in Castleman disease and in non-RA systemic inflammatory rheumatic diseases [39]. A possible new indication of TCZ might be a particular condition of inflammatory symmetrical erosive polyarthritis combined with clinical features of SLE [40], [41] and [42] known as "Rhupus". IL-6 levels are elevated in active Rhupus [42], and we successfully treated 3 patients of refractory Rupus who were at high risk for long lasting high dose of corticosteroids. TCZ, given monthly at the dose of $8 \mathrm{mg} / \mathrm{kg}$, allowed early reduction of corticosteroid dose even in 2 out of 3 patients who were corticosteroid-dependent, and resistant/intolerant to other biological drugs, including TNF-inhibitors, antiCD20, and ABA.

\section{Rituximab}

Rituximab (RTX), a monoclonal chimeric anti-CD20 antibody, recognizes a determinant expressed on intramedullary pre-B- to B-memory-stage lymphocytes. The first controlled trial on RA was published in 2004 [43]. Because B cells, the target of RTX, play pivotal roles in RA pathogenesis [44], serum biomarkers of $B$ cell activation, such as the presence of RF, or anti-CCP antibodies and elevated IgG level, were identified as potential predictors of response to RTX. Depleting the majority of circulating B-cells induces clinical remission which can last for many months before relapse [45]. Peripheral blood B cell re-population after RTX treatment is similar to what is observed after bone marrow transplantation, and predominantly involves a subset of naïve or antigenically inexperienced transitional B cells derived from an immature population. RTX is approved in the European Union and the USA for the treatment of RA after inadequate response to at least one TNF-inhibitor. It is currently prescribed as a second line treatment of active RA in association with methotrexate. However, in daily practice, RTX can be administered without methotrexate in patients with intolerance or previous adverse event to this drug [46]. The combination of RTX administered IV as two $1000 \mathrm{mg}$ infusion cycles separated by 15 days and methotrexate is highly effective at reducing disease activity at 6 months in RA. However, $35 \%$ of patients do not achieve a significant response and, among those who initially respond, relapse in the next 6-12 months often occurs [43]. A new cycle is initiated after disease activity recurs. The GISEA registry-based study showed a good efficacy for RTX with a mean reduction of DAS 28 at 52 weeks of more than 1.50 points, with maintenance over two years. No significant differences were observed for patients treated or not with MTX both for mean DAS 28 and $H A Q$ variation and achievement of disease remission [47].

Patients seronegative for rheumatoid factor and anti-cyclic citrullinated protein have worse responses, suggesting that these patients have non-B-cell-mediated disease and require a different therapeutic approach [48] and [49]. Despite the fact that RTX does not deplete fully matured plasma cells, repeated administration of the biologic agent frequently induces a reduction of immunoglobulins, particularly immunoglobulin $\mathrm{G}(\lg G)$, which may carry an increased risk of infection. 
Before commencement of RTX, hepatitis B serology and liver function tests should be routinely performed. Reactivation of occult hepatitis B infection has been reported in patients with RA treated with RTX. On the other hand specific safety profile of RTX indicates an apparent absence of increased risk of reactivation of tuberculosis, a low risk of opportunistic infections, but possibly a small increased risk of the very rare but serious neurological infection progressive multifocal leukoencephalopathy, the risk of which may be higher in patients with previous immunosuppression.

\section{References}

[1] A.D. Bankhurst, G. Husby, R.C. Williams Jr., Predominance of T cells in the lymphocytic infiltrates of synovial tissues in rheumatoid arthritis, Arthritis Rheum. 19 (3) (1976) 555-562.

[2] J.J. Cush, P.E. Lipsky, Phenotypic analysis of synovial tissue and peripheral blood lymphocytes isolated from patients with rheumatoid arthritis, Arthritis Rheum. 31 (10) (1988) 1230-1238.

[3] R.I. Fox, S. Fong, N. Sabharwal, S.A. Carstens, P.C. Kung, J.H. Vaughan, Synovial fluid lymphocytes differ from peripheral blood lymphocytes in patients with rheumatoid arthritis, J. Immunol. 128 (1) (1982) 351354.

[4] J.A. Van Boxel, S.A. Paget, Predominantly T-cell infiltrate in rheumatoid synovial membranes, N. Engl. J. Med. 293 (11) (1975) 517-520.

[5] M.C. Boissier, L. Semerano, S. Challal, N. Saidenberg-Kermanac'h, G. Falgarone, Rheumatoid arthritis: from autoimmunity to synovitis and joint destruction, J Autoimmun. 39 (2012) 222-228.

[6] M. Chabaud, J.M. Durand, N. Buchs, F. Fossiez, G. Page, L. Frappart, et al., Human interleukin-17: a T cell-derived proinflammatory cytokine produced by the rheumatoid synovium, Arthritis Rheum. 42 (1999) 963-970.

[7] L.W. Moreland, R. Alten, F. Van den Bosch, et al., Costimulatory blockade in patients with rheumatoid arthritis: a pilot, dose-finding, double-blind, placebo-controlled clinical trial evaluating CTLA-4Ig and LEA29Y eighty-five days after the first infusion, Arthritis Rheum. 46 (2002) 1470-1479.

[8] U. Grohmann, R. Bianchi, C. Orabona, F. Fallarino, C. Vacca, A. Micheletti, et al., Functional plasticity of dendritic cell subsets as mediated by CD40 versus B7 activation, J. Immunol. 171 (2003) 2581-2587.

[9] D.H. Munn, M.D. Sharma, A.L. Mellor, Ligation of B7-1/B7-2 by human CD4+ T cells triggers indoleamine 2,3-dioxygenase activity in dendritic cells, J. Immunol. 172 (2004) 4100-4110.

[10] J.M. Kremer, M. Dougados, P. Emery, P. Durez, J. Sibilia, W. Shergy, et al., Treatment of rheumatoid arthritis with the selective costimulation modulator abatacept: twelve-month results of a phase IIb, doubleblind, randomized, placebo-controlled trial, Arthritis Rheum. 52 (2005) 2263-2271.

[11] J.M. Kremer, H.K. Genant, L.W. Moreland, A.S. Russell, P. Emery, C. Abud-Mendoza, et al., Effects of abatacept in patients with methotrexate-resistant active rheumatoid arthritis: a randomized trial, Ann. Intern. Med. 144 (2006) 865-876.

[12] M. Schiff, M. Keiserman, C. Codding, S. Songcharoen, A. Berman, S. Nayiager, et al., Efficacy and safety of abatacept or infliximab vs placebo in ATTEST: a phase III, multi-centre, randomised, double-blind, 
placebo-controlled study in patients with rheumatoid arthritis and an inadequate response to methotrexate, Ann. Rheum. Dis. 67 (2008) 1096-1103.

[13] R. Westhovens, J.M. Kremer, P. Emery, A.S. Russell, R. Alten, E. Barré, M. Dougados, Long-term safety and efficacy of abatacept in patients with rheumatoid arthritis and an inadequate response to methotrexate: a 7-year extended study, Clin. Exp. Rheumatol. 32 (2014) 553-562.

[14] F. Atzeni, P. Sarzi-Puttini, C. Botsios, A. Carletto, P. Cipriani, E.G. Favalli, et al., Longterm anti-TNF therapy and the risk of serious infections in a cohort of patients with rheumatoid arthritis: Comparison of adalimumab, etanercept and infliximab in the GISEA registry, Autoimmun. Rev. 12 (2012) 225-229.

[15] F.B. Pallavicini, R. Caporali, P. Sarzi-Puttini, F. Atzeni, C. Bazzani, R. Gorla, et al., Tumor necrosis factor antagonist therapy and cancer development: analysis of the LORHEN registry, Autoimmun. Rev. 9 (2010) 175-180.

[16] I. Olivieri, P. Sarzi-Puttini, S. Bugatti, F. Atzeni, S. d'Angelo, R. Caporali, Early treatment in early undifferentiated arthritis, Autoimmun. Rev. 11 (2012) 589-592.

[17] F. Atzeni, P. Sarzi-Puttini, R. Gorla, A. Marchesoni, R. Caporali, Switching rheumatoid arthritis treatments: an update, Autoimmun. Rev. 10 (2011) 397-403.

[18] F. Atzeni, R. Talotta, M. Benucci, F. Salaffi, A. Cassinotti, V. Varisco, et al., Immunogenicity and autoimmunity during anti-TNF therapy, Autoimmun. Rev. 12 (2013) 703-770.

[19] M. Khraishi, A. Russell, W.P. Olszynski, Safety profile of abatacept in rheumatoid arthritis: a review, Clin. Ther. 32 (11) (Oct 2010) 855-870.

[20] J.D. Alves, A. Marinho, M.J. Serra, Tocilizumab: is there life beyond anti-TNF blockade? Int. J. Clin. Pract. 65 (2011) 508-513.

[21] L. Kaly, I. Rosner, Tocilizumab - a novel therapy for non-organ-specific autoimmune diseases, Best Pract. Res. Clin. Rheumatol. 26 (2012) 157-165.

[22] P.P. Tak, J.R. Kalden, Advances in rheumatology: new targeted therapeutics, Arthritis Res. Ther. 13 (2011) S5.

[23] N. Nishimoto, K. Yoshizaki, K. Maeda, et al., Toxicity, pharmacokinetics, and dose- finding study of repetitive treatment with the humanized anti-interleukin 6 receptor antibody MRA in rheumatoid arthritis. Phase I/II clinical study, J. Rheumatol. 30 (7) (2003) 1426-1435 (Phase I trial analyzing pharmacokinetics of tocilizumab (TCZ) in rheumatoid arthritis (RA) patients.).

[24] N. Nishimoto, T. Kishimoto, K. Yoshizaki, Anti-interleukin 6 receptor antibody treatment in rheumatic disease, Ann. Rheum. Dis. 59 (2000) 121-127.

[25] P.A. Guerne, B.L. Zuraw, J.H. Vaughan, et al., Synovium as a source of interleukin 6 in vitro: contribution to local and systemic manifestations of arthritis, J. Clin. Invest. 83 (1989) 585-9213.

[26] T. Hirano, T. Matsuda, M. Turner, et al., Excessive production of interleukin 6/B cell stimulatory factor2 in rheumatoid arthritis, Eur. J. Immunol. 18 (1988) 1797-1801. 
[27] F.A. Houssiau, J.P. Devogelaer, J. van Damme, et al., Interleukin-6 in synovial fluid and serum of patients with rheumatoid arthritis and other inflammatory arthritides, Arthritis Rheum. 31 (1988) 784-788.

[28] R. Madhok, A. Crilly, J. Watson, H.A. Capell, Serum interleukin 6 levels in rheumatoid arthritis: correlations with clinical and laboratory indices of disease activity, Ann. Rheum. Dis. 52 (1993) 232-234.

[29] U. Sack, R.W. Kinne, T. Marx, et al., Interleukin-6 in synovial fluid is closely associated with chronic synovitis in rheumatoid arthritis, Rheumatol. Int. 13 (1993) 45-51.

[30] S. Kotake, K. Sato, K.J. Kim, et al., Interleukin- 6 and soluble interleukin-6 receptors in the synovial fluids from rheumatoid arthritis patients are responsible for osteoclastlike cell formation, J. Bone Miner. Res. 11 (1996) 88-95.

[31] M. Mihara, K. Kasutani, M. Okazaki, et al., Tocilizumab inhibits signal transduction mediated by both mIL-6R and sIL-6R, but not by the receptors of other members of IL-6 cytokine family, Int. Immunopharmacol. 5 (12) (2005) 1731-1740.

[32] J.S. Smolen, A. Beaulieu, A. Rubbert-Roth, C. Ramos-Remus, J. Rovensky, E. Alecock, et al., Effect of interleukin-6 receptor inhibition with tocilizumab in patients with rheumatoid arthritis (OPTION study): a double-blind, placebo-controlled, randomised trial, Lancet 371 (9617) (2008) 987-997.

[33] Actemra Proscribing Information, Genentech, Inc.; A Member of Roche Group, South San Francisco, CA, USA, 2013. (Revised).

[34] J.S. Smolen, M.M. Schoels, N. Nishimoto, et al., Consensus statement on blocking the effects of interleukin- 6 and in particular by interleukin- 6 receptor inhibition in rheumatoid arthritis and other inflammatory conditions, Ann. Rheum. Dis. 72 (4) (2013) 482-492.

[35] European League Against Rheumatism (EULAR) Recommendations for Management. Available from http://www.eular.org/index.cfm?framePage/recommendations_management.cfm (Accessed on September 22, 2014).

[36] I. Al-Shakarchi, N.J. Gullick, D.L. Scott, Current perspectives on tocilizumab for the treatment of rheumatoid arthritis: a review, Patient Prefer. Adherence 7 (2013) 653-666.

[37] G.R. Burmester, A. Rubbert-Roth, A. Cantagrel, et al., A randomised, double-blind, parallel-group study of the safety and efficacy of subcutaneous tocilizumab versus intravenous tocilizumab in combination with traditional disease-modifying antirheumatic drugs in patients with moderate to severe rheumatoid arthritis (SUMMACTA study), Ann. Rheum. Dis. 73 (1) (2014) 69-74 (Phase III trial of TCZ evaluating the efficacy and safety of TCZ combination therapy by subcutaneous administration versus by intravenous administration in RA patients.).

[38] G. Jones, A. Sebba, J. Gu, et al., Comparison of tocilizumab monotherapy versus methotrexate monotherapy in patients with moderate to severe rheumatoid arthritis: the AMBITION study, Ann. Rheum. Dis. 69 (1) (2010) 88-96 (Pivotal Phase III trial showing that TCZ monotherapy is superior to methotrexate (MTX).).

[39] R. Alten, T. Maleitzke, Tocilizumab: a novel humanized anti-interleukin 6 (IL-6) receptor antibody for the treatment of patients with non-RA systemic, inflammatory rheumatic disease, Ann. Med. 45 (4) (2013) 357-363. 
[40] L.M. Amezcua-Guerra, R. Springall, R. Marquez-Velasco, et al., Presence against cyclic citrullinated peptides in patients with Rhupus: a cross-sectional study, Arthritis Res. Ther. 8 (5) (2006) R144.

[41] M. Satoh, A.K. Ajmani, M. Akizuki, What is the definition for coexistent rheumatoid arthritis and systemic lupus erythematosus? Lupus 3 (1994) 137-138.

[42] Eilertsen, C. Nikolaisen, A. Becker-Merok, J.C. Nossent, Interleukin-6 promotes arthritis and joint deformation in patients with systemic lupus erythematosus, Lupus 20 (2011) 607-613.

[43] J.C. Edwards, L. Szczepanski, J. Szechinski, A. Filipowicz-Sosnowska, P. Emery, D.R. Close, R.M. Stevens, T. Shaw, Efficacy of B-cell-targeted therapy with rituximab in patients with rheumatoid arthritis, N. Engl. J. Med. 350 (2004) 2572-2581.

[44] B. Marston, A. Palanichamy, J.H. Anolik, B cells in the pathogenesis and treatment of rheumatoid arthritis, Curr. Opin. Rheumatol. 22 (2010) 307-315.

[45] J.C. Edwards, G. Cambridge, M.J. Leandro, B cell depletion therapy in rheumatic disease, Best Pract. Res. Clin. Rheumatol. 20 (2006) 915e28.

[46] J.A. Markenson, A. Gibofsky, W.R. Palmer, et al., Persistence with anti-tumor necrosis factor therapies in patients with rheumatoid arthritis: observations from the RADIUS registry, J. Rheumatol. 38 (2011) 12731281.

[47] M. Sebastiani, M.G. Anelli, F. Atzeni, Efficacy and safety of rituximab with and without methotrexate in the treatment of rheumatoid arthritis patients: results from the GISEA register, Joint Bone Spine 81 (2014) 508-512.

[48] J. Sellam, H. Hendel-Chavez, S. Rouanet, et al., B cell activation biomarkers as predictive factors for the response to rituximab in rheumatoid arthritis, Arthritis Rheum. 63 (2001) 933-938.

[49] J.D. Isaacs, S.B. Cohen, P. Emery, et al., Effect of baseline rheumatoid factor and anticitrullinated peptide antibody serotype on rituximab clinical response: a meta-analysis, Ann. Rheum. Dis. 72 (2013) 329336. 